\title{
El abordaje de la memoria traumática desde un enfoque educativo
}

\author{
Tristán González Meyer | Técnico de turismo \\ URL de la contribución <www.iaph.es/revistaph/index.php/revistaph/article/view/5078>
}

Trabajar los lugares de memoria traumática presenta unas dificultades añadidas a la hora de patrimonializar sus recursos turísticos.

En primer lugar, tras hacer una evaluación de estos, hay que ver su potencial para ser transformados en un producto turístico y adaptarlo a las personas potenciales (y no potenciales) que visitarán los sitios, teniendo en cuenta, además, la carga histórica y política que llevan incorporada.

Los restos situados en Los Migueles, lugar de trincheras y fortificaciones de la guerra civil española, se recuperaron y se adaptaron para que pudieran ser visitados posteriormente, a través de tres campos de trabajo internacionales formados por un grupo de voluntarios guiados y asistidos por arqueólogos, historiadores y museólogos.

Bajo nuestra experiencia, el público que visita los restos de la batalla del Jarama, situados en el término munici-

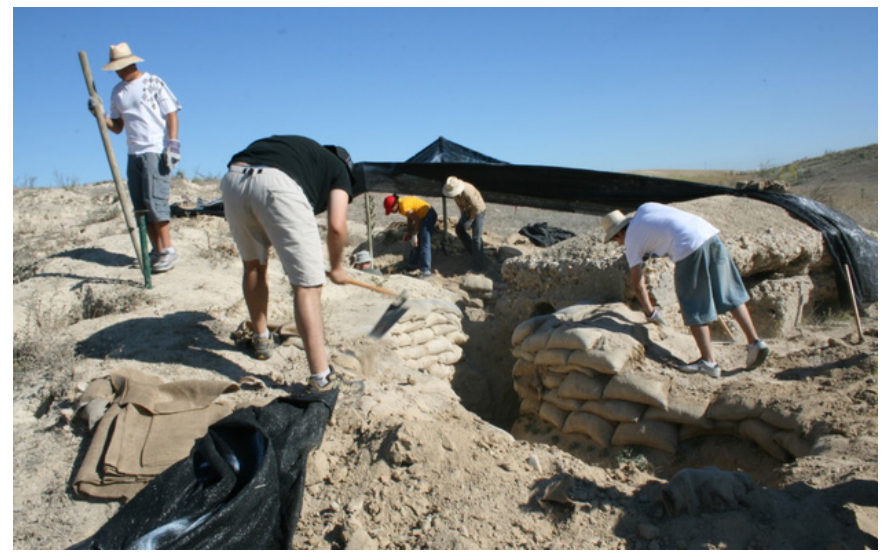

Recuperación de trincheras | foto GEFREMA pal de Rivas-Vaciamadrid, presentan una serie de diferentes inquietudes que les llevan a realizar esta visita: por un lado, hay personas interesadas por los conflictos bélicos del pasado, conocedoras del tipo de armamento empleado en esta contienda, de quiénes estaban al mando de cada batallón y de las estrategias militares plasmadas sobre el terreno en las diferentes construcciones (búnkeres, trincheras, fortificaciones, etc.); por otro lado encontramos visitantes con intereses histórico-políticos que quieren reconocer a quienes lucharon en la Guerra Civil; y, finalmente, grupos de estudiantes (de Enseñanza Secundaria Obligatoria o Bachillerato) cuyos profesores quieren consolidar, con una vista sobre un escenario real, lo enseñado en el aula.

De todos los perfiles mencionados, el más interesante bajo mi punto de vista es el de trabajar este lugar de memoria traumática desde la educación reglada, debido a que los y las estudiantes son el futuro de nuestra sociedad y en sus manos estará, habiendo aprendido del pasado común, el evitar conflictos.

Esto plantea una serie de dilemas que se deben abordar, y no suele ser fácil hacerlo. Hay que compaginar, de forma trasversal, los conocimientos históricos con los que marcan las administraciones.

En las visitas realizadas a grupos escolares se les entrega un material de apoyo para la visita didáctica, que tiene dos finalidades: por una parte dar a conocer la dura vida cotidiana en un campo de batalla y cómo se sentían las personas que tuvieron que estar sufriendo esas dolorosas vivencias; y por otro lado conseguir que los alumnos que visitan el lugar sean capaces de plantear opciones sobre cómo se podría haber evitado "todo aquello". 


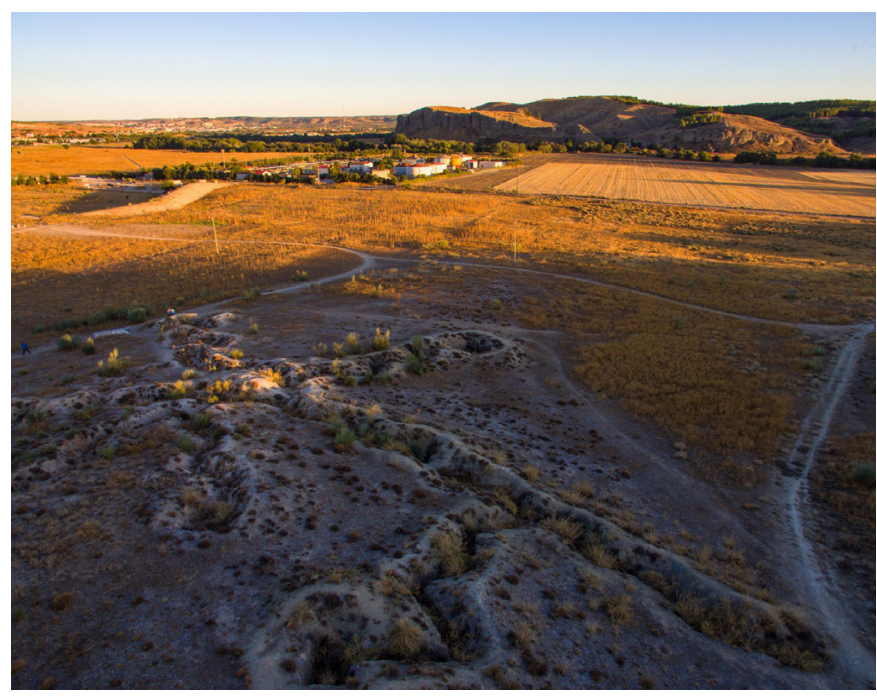

Foto aérea segunda línea de defensa del Frente Republicano

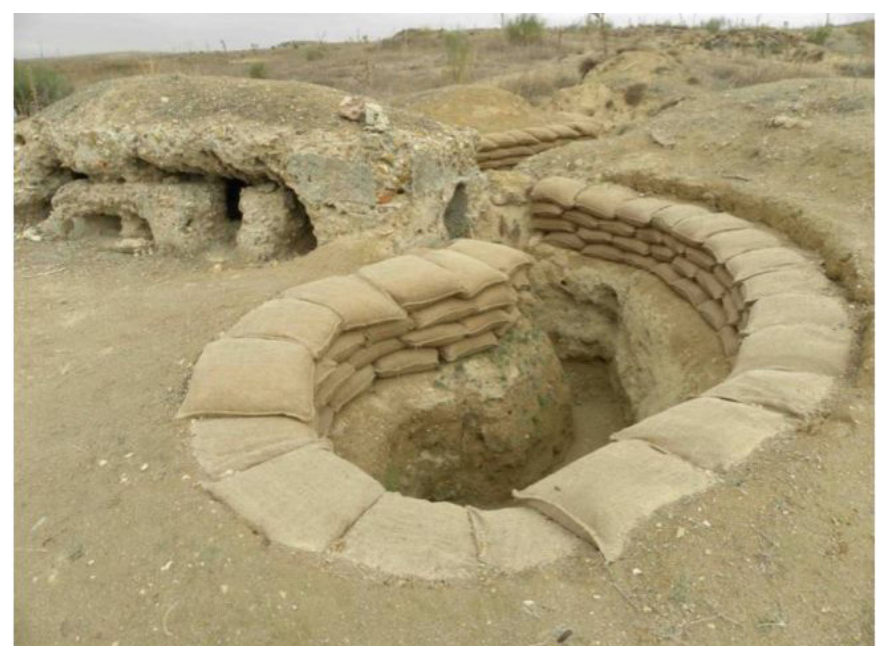

Puesto de escuadra y pozo granadero | fotos Guillermo González Meyer

Se trata de que los visitantes se pongan en la situación y puedan llegar a sentir el miedo e incluso el mal olor que hubo en ese lugar. En un marco de educación para la no violencia (educación para la paz), y siendo conocedores de cómo hoy en día se han podido evitar conflictos bélicos a través de una protección, una mediación o una supervisión, se pretende que el alumnado sea capaz de buscar alternativas para que "aquello" no hubiese llegado a suceder, y cumplir así con los objetivos señalados anteriormente.
Este material didáctico sí se orienta al trabajo de las competencias sensitivas y emocionales, apostando por la inclusión y participación de los grupos de escolares en la visita a Los Migueles.

Al poder pasear, adentrarse en las trincheras y túneles recuperados, los visitantes se ponen en el lugar de los soldados. Es un terreno árido, muy frío en invierno y tremendamente caluroso en verano, los días que llueve el fango cubre las botas. Las personas experimentan un cambio muy significativo entre el inicio y el final del recorrido. Y ese es el objetivo principal, empatizar con quien ocupó ese lugar hace 84 años.

Es imprescindible la puesta en valor de este tipo de patrimonio, tratar este espacio de memoria traumática desde un punto objetivo, trasladando a las personas los conocimientos necesarios para que interpreten este espacio de historia viva e incorporen a su existencia una experiencia única y diferente. 